\title{
Mechanisms of magnesium-induced vasodilation in cerebral penetrating arterioles
}

\author{
Takahiro Murata, M.D. ${ }^{1}$, Hans H. Dietrich, Ph.D. ${ }^{2,3}$, Tetsuyoshi Horiuchi, M.D. ${ }^{1}$, Kazuhiro \\ Hongo, M.D. ${ }^{1}$, and Ralph G. Dacey Jr., M.D. ${ }^{2}$ \\ ${ }^{1}$ Department of Neurosurgery, Shinshu University School of Medicine, Matsumoto 390-8621, \\ Japan \\ 2Department of Neurological Surgery, Washington University School of Medicine, St. Louis, \\ Missouri 63110, United States \\ ${ }^{3}$ Hope Center for Neurological Disorders, Washington University School of Medicine, St. Louis, \\ Missouri 63110, United States
}

\begin{abstract}
We investigated in cerebral penetrating arterioles the signaling mechanisms and dose-dependency of extracellular magnesium-induced vasodilation and also its vasodilatory effects in vessels preconstricted with agonists associated with delayed cerebral vasospasm following SAH. Male rat penetrating arterioles were cannulated. Their internal diameters were monitored. To investigate mechanisms of magnesium-induced vasodilation, inhibitors of endothelial function, potassium channels and endothelial impairment were tested. To simulate cerebral vasospasm we applied several spasmogenic agonists. Increased extracellular magnesium concentration produced concentration-dependent vasodilation, which was partially attenuated by non-specific calciumsensitive potassium channel inhibitor tetraethylammonium, but not by other potassium channel inhibitors. Neither the nitric oxide synthase inhibitor L-NNA nor endothelial impairment induced by air embolism reduced the dilation. Although the magnesium-induced vasodilation was slightly attenuated by the spasmogen ET-1, neither application of $\mathrm{PF}_{2 \mathrm{a}}$ nor $\mathrm{TXA}_{2}$ analog effect the vasodilation. Magnesium induced a concentration- and smooth muscle cell-dependent dilation in cerebral penetrating arterioles. Calcium-sensitive potassium channels of smooth muscle cells may play a key role in magnesium-induced vasodilation. Magnesium also dilated endothelium-impaired vessels as well as vessels preconstricted with spasmogenic agonists. These results provide a fundamental background for the clinical use of magnesium, especially in treatment against delayed cerebral ischemia or vasospasm following SAH.
\end{abstract}

Corresponding author: Takahiro Murata, M.D., ; Email: tmurata@ shinshu-u.ac.jp, Department of Neurosurgery, Shinshu University School of Medicine, 3-1-1 Asahi, Matsumoto 390-8621, Japan, Phone number: +81 (263) 37-2690, Fax number: +81 (263) 37-0480 Disclosures

We declare that we have no conflicts of interest.

Publisher's Disclaimer: This is a PDF file of an unedited manuscript that has been accepted for publication. As a service to our customers we are providing this early version of the manuscript. The manuscript will undergo copyediting, typesetting, and review of the resulting proof before it is published in its final citable form. Please note that during the production process errors may be discovered which could affect the content, and all legal disclaimers that apply to the journal pertain. 


\section{Keywords}

cerebral penetrating arterioles; delayed cerebral vasospasm; magnesium; subarachnoid hemorrhage; potassium channels

\section{Introduction}

Development of delayed cerebral ischemia (DCI) following subarachnoid hemorrhage (SAH), which results in an unfavorable clinical outcome, is thought to be caused by the combined effects of delayed cerebral vasospasm, arteriolar constriction and microthrombosis, cortical spreading ischemia, and processes triggered by early brain injury (Macdonald, 2014). Delayed cerebral vasospasm is one of the major causes of DCI, however, its pathophysiological mechanisms still remain unresolved despite progress in experimental and human investigations, thus limiting the number of available effective therapies. Magnesium is a well-known neuroprotective as well as vasodilatory agent with various experimental and clinical profiles. Several clinical studies have demonstrated the safety and efficacy of intravenous magnesium therapy for aneurysmal SAH (Veyna et al., 2002; van den Bergh et al., 2003). Unfortunately, the "Magnesium in Aneurysmal Subarachnoid Hemorrhage" (MASH-2) study, a phase III randomized, clinical, international multicenter trial, recently indicated that intravenous magnesium sulfate infusion therapy failed to improve clinical outcome after aneurysmal SAH (Dorhout Mees et al., 2012). These trials suggested that magnesium, administered in addition to the oral calcium blocker nimodipine, may not improve neuroprotection in patients when given intravenously. In contrast, Mori et al. (Mori et al., 2009a; Mori et al., 2009b) demonstrated that intracisternal injection of magnesium sulfate solution has a vasodilatory effect on spastic cerebral arteries both in human aneurysmal SAH and canine SAH models. In addition, we recently reported that increased extracellular magnesium concentration $\left(\left[\mathrm{Mg}^{2+}\right]_{\mathrm{o}}\right)$ significantly induced dilation in cerebral penetrating arterioles (Murata et al., 2011); however, little is known regarding the vasodilatory mechanisms of magnesium in the cerebral microcirculation. These vessels play an important role in the regulation of the cerebral circulation by maintaining normal blood flow and pressure to protect against cerebral ischemia and infarction (Faraci and Heistad, 1990; Nishimura et al., 2007). The failure of microvascular regulation after SAH suggests a pivotal role in the development and size of ischemia (Dietrich and Dacey, 2000). Therefore, the purpose of the present study was to clarify the signaling mechanisms of vasodilation induced by increased $\left[\mathrm{Mg}^{2+}\right]_{\mathrm{o}}$ in cerebral penetrating arterioles as it would occur after intracisternal magnesium injection in vivo and also to determine magnesium's vasodilatory potency in vessels preconstricted with spasmogen involved in delayed cerebral vasospasm following SAH.

\section{Materials and Methods}

\section{Isolation and cannulation of cerebral penetrating arterioles}

All experimental procedures in this study were approved by the Washington University Advisory Committee for Animal Resources. The detailed techniques used in this study for the dissection and cannulation of intracerebral arterioles have also been described previously 
(Dacey and Duling, 1982). Briefly, fifty male Sprague-Dawley rats (300-450 g, 14-20 weeks olds, Harlan, Indianapolis, IN) were anesthetized (86.98 mg/kg ketamine; 13.40 $\mathrm{mg} / \mathrm{kg}$ xylazine, intraperitoneally) and sacrificed. The brain was rapidly removed from the skull and placed in a cooled $\left(4^{\circ} \mathrm{C}\right)$ dissection chamber filled with physiological saline solution (PSS; see below) containing 1\% dialyzed bovine serum albumin (BSA). Under a surgical microscope, a 2-3 mm slab of the cerebral cortex containing the middle cerebral artery (MCA) was dissected from the brain. The pia mater was gently reflected from the parenchyma to expose the intracerebral arterioles from MCA. The isolated arteriole was carefully transferred from the dissection chamber to a temperature-controlled vessel chamber (2.5-ml organ bath) mounted on the stage of an inverted video microscope (Zeiss TV 200, Thornton, NY). The holding and perfusion pipettes used for cannulation were fabricated by pulling and shaping glass tubes (Drummond Scientific Co.; $2.13 \mathrm{~mm}$ O.D., $1.63 \mathrm{~mm}$ I.D., and $1.19 \mathrm{~mm}$ O.D., $1.02 \mathrm{~mm}$ I.D., respectively; 15-cm length) using a microforge (Stoelting Co., Wood Dale, IL). The collecting pipettes were also fabricated from the same glass as the holding pipettes (2.13 mm O.D., $1.63 \mathrm{~mm}$ I.D.). The final holding pipette diameter was $80-90 \mu \mathrm{m}$ and perfusion pipette diameter was $45-50 \mu \mathrm{m}$. The unbranched penetrating arteriole was cannulated at one end with the concentrically mounted perfusion (inner) and holding (outer) pipette system. The opposite end of the arteriole was occluded by the collecting pipette. All experiments were conducted without intraluminal flow. The transmural pressure $(60 \mathrm{mmHg})$ was monitored continuously with a pressure transducer (model P23, Gould, Cleveland, $\mathrm{OH}$ ) and recorded on a strip chart recorder (model 3200 , Gould). The internal diameter of the vessel was observed with a high-resolution videocamera (CCD 72 with GenIIsis, Dage-MTI, Michigan City, IN) and displayed on a monitor. To measure the internal vessel diameter, we used both a calibrated videodimensional analyzer (modified model 321, Colorado Video) and Diamtrak Edge-tracking software (T.O. Neild, Flinders University, Adelaide, Australia) as previously described (Neild, 1989). This method uses a video microscope to produce a digitized image of the blood vessel, the video signal was acquired on-line by a computerized diameter tracking system, allowing for a diameter measurement at a spatial resolution of $0.5 \mu \mathrm{m} / \mathrm{pixel}$ and a data acquisition rate of $10 \mathrm{~Hz}$. The data were digitally stored as well as recorded on a stripchart recorder for later evaluation. The vessel chamber temperature was increased to $37.5^{\circ} \mathrm{C}$, and the arterioles were allowed to develop spontaneous tone over approximately 45 minutes. The organ bath was continually replaced with a fresh PSS (pH7.3) of the following composition (in mmol/L): $144 \mathrm{NaCl}, 3.0 \mathrm{KCl}, 2.5 \mathrm{CaCl} 2,1.4 \mathrm{MgSO}$, 2.0 pyruvate, 5.0 glucose, 0.02 ethylenediaminetetraacetic acid (EDTA), $1.21 \mathrm{NaH} 2 \mathrm{PO}$, and $2.03-(\mathrm{N}-$ morpholino)propanesulfonic acid (MOPS) without BSA at a constant flow rate $(0.5 \mathrm{ml} / \mathrm{min})$ with a peristaltic pump (model 203, Scientific Industries, Bohemia, NY). After an equilibration period, the arterioles developed spontaneous tone, and we assessed their responsiveness and viability by changing the extraluminal $\mathrm{pH}$ from 7.3 to 6.8 and from 7.3 to 7.65. Arterioles with poor tone (less than $20 \%$ decrease from the maximal passive diameter) or poor response to $\mathrm{pH}$ (less than $15 \%$ change in diameter after $\mathrm{pH}$ change) were excluded. In some vessels, we compared vessel tone and $\mathrm{pH}$-induced responses at the beginning and end of experiments to confirm the stability of the preparation. 


\section{Experimental procedures}

After cannulation and development of spontaneous tone we tested the vessel response to $\mathrm{pH}$ 6.8 and $\mathrm{pH} 7.65$ to confirm vessel viability. Then we measured the vessel diameter dose response to increasing extraluminal magnesium concentrations $(2.1,2.8,3.5,4.2 \mathrm{mmol} / \mathrm{L}$, respectively) with a control $\left[\mathrm{Mg}^{2+}\right]_{\mathrm{o}}$ of $1.4 \mathrm{mmol} / \mathrm{L}$ after an equilibration period of $10-15$ min for each concentration. The chosen increases in magnesium concentrations reflect physiologically and clinically relevant increases in $\left[\mathrm{Mg}^{2+}\right]_{\mathrm{o}}$ avoiding hypermagnesemia. Recovery back to control was also measured. To study the mechanisms involved in magnesium-induced vasodilation, we repeated the magnesium dose-response either after endothelial impairment or in the presence of inhibitors or spasmogens after equilibration ( 60 minutes). To study the contribution of the endothelium on magnesium-induced vasodilation, the endothelium was impaired by passage of air through the arteriole at 60 $\mathrm{mmHg}$ intraluminal pressure. Air embolization does not necessarily remove the endothelium but has been shown to disrupt the endothelium in microvessels (Saito et al., 1994), and we previously confirmed to use sodium nitroprusside to ensure that vascular smooth muscle dilation was not changed before and after air embolization (Horiuchi et al., 2001). To assess endothelial damage, we applied adenosine tri-phosphate (ATP) extraluminally before and after air embolism. Complete endothelial impairment was confirmed by lack of dilation of ATP (Horiuchi et al., 2001). L-NNA (N $\omega$-Nitro-L-arginine, $10 \mu \mathrm{mol} / \mathrm{L}$ ) was used to inhibit endothelial nitric oxide (NO) production. Four potassium channel inhibitors were used as followed: 1) $30 \mu \mathrm{mol} / \mathrm{L} \mathrm{BaCl}_{2}$ (inward rectifier potassium ( $\mathrm{K}_{\mathrm{IR}}$ ) channel inhibitor); 2) 1 $\mathrm{mmol} / \mathrm{L}$ tetraethylammonium, (TEA, non-specific calcium-sensitive potassium $\left(\mathrm{K}_{\mathrm{Ca}}\right)$ channel inhibitor); 3) $100 \mu \mathrm{mol} / \mathrm{L}$ 4-aminopyridine (4-AP, voltage-dependent potassium $\left(\mathrm{K}_{\mathrm{V}}\right)$ channel inhibitor); 4) $3 \mu \mathrm{mol} / \mathrm{L}$ glibenclamide (ATP-sensitive potassium $\left(\mathrm{K}_{\mathrm{ATP}}\right.$ ) channel inhibitor). To simulate delayed cerebral vasospasm we applied several vasospasmrelated vasoconstrictors including Endothelin-1 (ET-1, 1-21 peptides), Prostaglandin $F_{2 a}$ $\left(\mathrm{PF}_{2 \mathrm{a}}\right)$ and Thromboxane $\mathrm{A}_{2}\left(\mathrm{TXA}_{2}\right)$ analog $(\mathrm{U} 46619)$. All chemicals were applied extraluminally and obtained from Sigma-Aldrich, St. Louis, MO.

\section{Statistical analysis}

All data are presented as mean \pm SEM, with $n$ representing the number of observations. Statistics were conducted on absolute vessel diameters. All data analysis was done using a statistical software package (InStat, GraphPad Software, San Diego, CA). Differences were considered significant at $P<0.05$ and determined by analysis of paired and Student's t-test. The data are presented as percent maximum diameter to correct for changed control diameters induced by treatments and was calculated the following formula: \% maximum dilation $=\left[\left(D_{\text {after }}-D_{\text {before }}\right) /\left(D_{\max }-D_{\text {before }}\right)\right]^{*} 100$, where $D_{\max }$ is maximal passive diameter of the vessel at $60 \mathrm{~mm} \mathrm{Hg}$ before the development of spontaneous tone, and $\mathrm{D}_{\text {before }}$ is the baseline diameter of the arteriole before increase of $\left[\mathrm{Mg}^{2+}\right]_{0}$ and $\mathrm{D}_{\mathrm{after}}$ are the arteriolar diameter after the each of increased $\left[\mathrm{Mg}^{2+}\right]_{0}$. 


\section{Results}

\section{Magnesium induced arteriolar vasodilatory responses}

Intact cerebral penetrating arterioles had a maximal passive diameter of $76.67 \pm 1.56 \mu \mathrm{m}$ $(\mathrm{n}=35)$, and spontaneous tone diameter of $54.53 \pm 1.23 \mu \mathrm{m}$ (baseline, $-28.92 \pm 0.50 \%$ of their maximal passive diameter).

Increase of $\left[\mathrm{Mg}^{2+}\right]_{\mathrm{o}}$ significantly induced concentration-depended vasodilation (Fig. 1).

\section{Mechanistic studies}

Endothelial impairment after air embolism resulted in decreased arteriolar diameter (Table 1) and reduced dilation to $100 \mu \mathrm{mol} / \mathrm{L}$ of ATP (data not shown) indicating effective endothelial impairment. However, endothelial impairment did not affect the magnesiuminduced vasodilation (Fig. 2A). Application of L-NNA (10 $\mu \mathrm{mol} / \mathrm{L})$ constricted the arterioles (Table 1) indicating eNOS activity. Pretreatment of intact arterioles with L-NNA (10 $\mu \mathrm{mol} / \mathrm{L}$ ) did not inhibit the vasodilatory response to increases in the $\left[\mathrm{Mg}^{2+}\right]_{\mathrm{o}}$ (Fig. 2B). We next investigated whether vasodilation induced by increased $\left[\mathrm{Mg}^{2+}\right]_{0}$ was dependent on potassium channel activity. Application of TEA $(1 \mathrm{mmol} / \mathrm{L})$ significantly attenuated the vasodilation to magnesium(Fig. 3A). However, combined $\mathrm{BaCl}_{2}$ (30 $\left.\mu \mathrm{mol} / \mathrm{L}\right)$, 4-AP (100 $\mu \mathrm{mol} / \mathrm{L})$ and glibenclamide $(3 \mu \mathrm{mol} / \mathrm{L})$ had no effect on the magnesium-induced vasodilation (Fig. 3B).

\section{Magnesium-induced vasodilation on preconstricted vessels}

The next experiments were performed to study whether increase in the $\left[\mathrm{Mg}^{2+}\right]_{\mathrm{o}}$ dilates vessels preconstricted with cerebral vasospasmogens. To obtain the suitable preconstriction (approximately 10\% relative change in diameter), increasing concentrations of each vasoconstrictor were applied to the arterioles $(n=15)$. The delayed cerebral vasospasmogens ET-1, $\mathrm{PF}_{2 \mathrm{a}}$ and $\mathrm{TXA}_{2}$ analog, significantly induced concentration dependent vasoconstriction (data not shown). Table 1 summarizes the vasoconstrictory response to the spasmogens at the concentrations used. Although the magnesium-induced vasodilation was slightly attenuated by ET-1 (10 pmol/L), neither application of $\mathrm{PF}_{2 a}(100 \mathrm{nmol} / \mathrm{L})$ nor $\mathrm{TXA}_{2}$ analog $(10 \mathrm{nmol} / \mathrm{L})$ affected the vasodilatory response to increased $\left[\mathrm{Mg}^{2+}\right]_{\mathrm{o}}$ (Fig. $\left.4 \mathrm{~A}-\mathrm{C}\right)$.

\section{Discussion}

The major findings of the present study are: 1) Physiologically and clinically relevant increased in extracellular magnesium concentration produced concentration-dependent vasodilation in cerebral penetrating arterioles; 2) This vasodilation was partially attenuated by non-specific calcium-sensitive potassium channel inhibitor TEA, but not by voltagedependent potassium channel inhibitor 4-AP, ATP-sensitive potassium channel inhibitor glibenclamide, and inward rectifier potassium channel inhibitor $30 \mu \mathrm{mol} / \mathrm{L} \mathrm{BaCl}_{2} ; 3$ ) Neither the NO synthase inhibitor L-NNA nor endothelial impairment induced by air embolism reduced the dilation; 4) The magnesium-induced vasodilation was unaffected in constricted arterioles with delayed cerebral vasospasm-related agents including $\mathrm{PF}_{2 \mathrm{a}}$ and $\mathrm{TXA}_{2}$ analog, but partially reduced by ET-1. Collectively, these results indicate that magnesium-induced 
dilation of penetrating arterioles partially depends $\mathrm{K}_{\mathrm{Ca}}$ channels of smooth muscle cells but is not endothelium-dependent and has a vasodilatory capacity in the presence of cerebrovascular spasmogens. These new findings may provide a fundamental background for the clinical use of magnesium, especially in treatment of delayed cerebral ischemia or vasospasm following SAH.

\section{Magnesium-induced vasodilation and endothelium}

Magnesium has similar properties as calcium antagonist and is considered a physiological calcium blocker. The main action of magnesium on vascular smooth muscle is thought to decrease intracellular calcium through the inhibition of calcium influx and the blockage of calcium release from the sarcoplasmic reticulum (Altura et al., 1987). The main effect of decreased intracellular calcium would be inactivation of calmodulin-dependent myosin light chain kinase activity and decreased vascular contraction inducing arterial relaxation (Altura et al., 1987).

The vasodilatory effect of magnesium sulfate has been investigated in various vessels both in vivo and in vitro animal. However, the vasodilatory mechanism was found to vary between preparations and has not been studied in cerebral arterioles as major resistance vessel managing cerebral blood flow. In large conduit artery, Yang et al (Yang et al., 2000) demonstrated that the relaxation to magnesium in male rat aorta is reduced in absence of endothelium as well as in the presence of the NO synthase inhibitor L-NAME and proposed that magnesium-induced vasorelaxation partially depends on the endothelium where magnesium increases NO production. Longo et al (Longo et al., 2001) also showed that in aorta from late pregnant female rat (but not female rat at term pregnancy) the relaxation to magnesium is decreased after endothelial impairment and L-NAME and proposed that magnesium-induced vasorelaxation partially depends on both endothelium and gestational age. The above results indicate that in large conductance vessels magnesium directly acts both on smooth muscle and endothelial cells to cause vasodilation. Extracellular magnesium likely modulates calcium-dependent endothelial relaxation factor production (NO) (Altura et al., 1987; Gold et al., 1990) by antagonizing endothelial calcium increases (Ku and Ann, 1987). In smaller resistance vessels, however, the present experiments demonstrate that magnesium-induced vasodilation was not affected by either pretreatment of the NOS inhibitor L-NNA or endothelial impairment induced by air embolism. These date clearly suggest that at least the direct vasodilatory action of magnesium is not linked to the release of NO in this preparation. It is possible that other endothelial relaxation factors such as prostacyclin or endothelium derived hyperpolarization factor (EDHF) contribute to endothelium-mediated dilation to magnesium. Magnesium has been demonstrated to increase prostacyclin production in cultured human umbilical vein endothelial cells (Watson et al., 1986). The cyclooxygenase inhibitor indomethacin attenuated magnesium-induced vasorelaxation in pregnant rat aorta, and prostacyclin may also synergistically interact with magnesium in smooth muscle cells of large conduit artery (Longo et al., 2001). However, our experiments show that endothelial impairment did not attenuate the magnesium-induced vasodilation and indicate that other endothelial relaxation factors such as prostacyclin or EDHF may not contribute to the vasodilatory effect of magnesium in the cerebral microcirculation. 


\section{Magnesium-vasodilation and potassium channel activation on vascular smooth muscle cells}

Several studies have demonstrated that magnesium activates potassium channels and results in membrane hyperpolarization which initiates the relaxation of smooth muscle cells (Ko et al., 2008; Thorneloe and Nelson, 2005). In the present study, the vasodilation induced by magnesium persisted after inhibiting endothelial function but was attenuated by non-specific $\mathrm{K}_{\mathrm{Ca}}$ channels inhibitor TEA. This indicates that $\mathrm{K}_{\mathrm{Ca}}$ channels on the vascular smooth muscle cells rather than on endothelial cells contribute to magnesium-induced penetrating arteriolar dilation. The $\mathrm{K}_{\mathrm{Ca}}$ channels are expressed in various vascular smooth muscle cells of various animals and include small-, intermediate-, and large conductance calciumsensitive potassium $\left(\mathrm{SK}_{\mathrm{Ca}}, \mathrm{IK}_{\mathrm{Ca}}\right.$, and $\mathrm{BK}_{\mathrm{Ca}}$ ) channels (Eichhorn and Dobrev, 2007). In a previous study we confirmed that $\mathrm{BK}_{\mathrm{Ca}}$ and $\mathrm{IK}_{\mathrm{Ca}}$ but not $\mathrm{SK}_{\mathrm{Ca}}$ channels contribute to purinergic dilation in penetrating arterioles (Dietrich et al., 2009). Further, only intraluminal inhibition of $\mathrm{IK}_{\mathrm{Ca}}$ was effective indicating that $\mathrm{IK}_{\mathrm{Ca}}$ channels are expressed on endothelial cells. These observations indicate that vascular smooth muscle $\mathrm{BK}_{\mathrm{Ca}}$ channels may be responsible for the observed dilation to extracellular magnesium. While SK and IK channels are activated by increase of the intracellular calcium concentration, $\mathrm{BK}_{\mathrm{Ca}}$ channels are known to be activated by membrane depolarization and intracellular calcium as well as intracellular magnesium (Shi and Cui, 2001; Zhang et al., 2001), further supporting the smooth muscle $\mathrm{BK}_{\mathrm{Ca}}$ channel as a mediator of magnesium-induced penetrating arteriolar dilation. A possible mechanism to explain the activation of $\mathrm{BK}_{\mathrm{Ca}}$ channels induced by increased $\left[\mathrm{Mg}^{2+}\right]_{\mathrm{o}}$ suggests direct binding of magnesium to the $\mathrm{BK}_{\mathrm{Ca}}$ channels (Zhang et al., 2001). In cultured smooth muscle cells from rat aorta, the increasing $\left[\mathrm{Mg}^{2+}\right]_{\mathrm{o}}$ elevated the intracellular magnesium concentration $\left[\mathrm{Mg}^{2+}\right]_{\mathrm{i}}$ (Zhang et al., 1992), and the changing of $\left[\mathrm{Mg}^{2+}\right]_{\mathrm{i}}$ may lead the activation of $\mathrm{BK}_{\mathrm{Ca}}$ channels resulting in vasodilation. Alternatively, because intracellular magnesium also blocks Kir channels (Matsuda et al., 1987), blocking of Kir channels would result in membrane depolarization and subsequent $\mathrm{BK}_{\mathrm{Ca}}$ channel activation. However, since inhibiting Kir channels in our preparation did not lead to an arteriolar dilation, it is unlikely that such a mechanism is involved. Our studies indicate that smooth muscle $\mathrm{K}_{\mathrm{Ca}}$ channels contribute to magnesium-induced cerebral arteriolar dilation. However, further studies are needed to determine the potassium channel sub-type and the mechanism for the channel activation.

In this study, magnesium-induced vasodilation was only partially suppressed by non-specific $\mathrm{K}_{\mathrm{Ca}}$ channels inhibitor TEA. A possible mechanism to explain the residual vasodilation may the blocking of smooth muscle calcium channel activity by increased $\mathrm{Mg}^{2+}$. The sustained calcium influx via L-type calcium channels into vascular smooth muscle leads the activation of various second messenger systems that results in vasoconstriction. Magnesium sulfate suppressed the calcium currents through L-type calcium channels in smooth muscle cells isolated from rabbit basilar artery (Sharma et al., 2012). More studies are needed to explore this hypothesis.

\section{Magnesium therapy for SAH}

Numerous factors may lead to the development of delayed cerebral vasospasm following SAH. Endothelial dysfunction resulting in reduced production of vasodilators and enhanced 
production of vasoconstrictors, phenotypic changes of the receptors in endothelium and smooth muscle cells, increased sensitivity to vasoconstrictors in smooth muscle cells, release of spasmogens from lysed blood clots and inflammatory responses of the vascular wall have been indicated as pathophysiological mechanisms participating in the development of vasospasm. Potent vasoconstrictors such as ET-1, $\mathrm{PF}_{2 \mathrm{a}}$ and $\mathrm{TXA}_{2}$ may have a key role in the cascade of vasospasm-inducing events (Fassbender et al., 2000; Hempelmann et al., 1997; Asaeda et al., 2005). In the present study, magnesium-induced dilation was not inhibited by $\mathrm{PF}_{2 \mathrm{a}}$ orTXA $\mathrm{A}_{2}$ and ET-1 reduced the magnesium-induced dilation only by $\sim 10 \%$. ET-1 is the most powerful vasoconstrictor which exerts its primary actions through $\mathrm{G}$ protein coupled receptors, the $\mathrm{ET}_{\mathrm{A}}$ and $\mathrm{ET}_{\mathrm{B}}$ receptors, in the cerebral arteries. Molecular signaling pathways of ET-1 are thought that increased intracellular calcium concentration is induced via phospholipase C and protein kinase C activation (Dietrich and Dacey, 2000). Magnesium may cause insufficient vasodilation in the intracerebral arterioles with ET-1 because of increased intracellular calcium concentration. Although ET-1 slightly attenuated the magnesium-vasodilation, the arterioles dilated concentration-dependently. Higher magnesium concentrations may result in greater dilation of the arterioles.

The MASH-2 study did not demonstrate improvement of clinical outcome in patients with SAH using intravenous magnesium sulfate infusion. One of the limiting factors in this study may be the difference of magnesium concentrations between serum and cerebrospinal fluid (CSF) (Dorhout Mees et al., 2012). Intravenous magnesium administration leads to only limited increases in magnesium concentration in CSF. The neuroprotective and cerebral vasodilatory effect may depend on sufficient magnesium concentration in CSF. Higher magnesium concentration in CSF can be achieved by intracisternal magnesium infusion though the infusion still have required invasive techniques with drain from CSF space and have an inherent risk of complications (Mori et al., 2009b). Intracisternal magnesium infusion therapy may ameliorate delayed cerebral vasospasm and result in the improvement of the clinical outcome in patients with SAH. As such our experimental approach is consistent with the use of intracisternal magnesium injection to achieve sufficient extracellular therapeutically sufficient magnesium concentrations. Our findings with SAHrelated vasoconstrictors indicated that the dilation of the constricted penetrating arterioles induced by increased concentration of magnesium will provide a fundamental background for the clinical use of magnesium sulfate, especially in treatment against delayed cerebral vasospasm. In conclusion, magnesium induced concentration- and smooth muscle cellsdependent dilation in cerebral penetrating arterioles. $\mathrm{K}_{\mathrm{Ca}}$ channels of smooth muscle cells may play a key role in magnesium-induced vasodilation. Magnesium also dilated the endothelium-impaired vessels or preconstricted vessels with vasospasmogens. These results support the use of magnesium therapy in treating delayed cerebral ischemia or vasospasm following SAH.

\section{Acknowledgments}

Support provided by: Project Grants from the National Institute Health (NIH P01 NS32636; NIH R01 HL041250; NIH R01 NS30555) and Barnes-Jewish Hospital Foundation to Hans H. Dietrich, and Grant-in-Aid for Scientific Research (KAKENHI) (24890079; 25462210) to Takahiro Murata

Sources of Funding

Neurosci Res. Author manuscript; available in PMC 2017 June 01. 
This study was supported by Project Grants from the National Institute Health (NIH P01 NS32636; NIH R01 HL041250; NIH R01 NS30555), Barnes-Jewish Hospital Foundation, and Grant-in-Aid for Scientific Research (KAKENHI) (24890079; 25462210).

\section{References}

Altura BM, Altura BT, Carella A, Gebrewold A, Murakawa T, Nishio A. Mg2+-Ca2+ interaction in contractility of vascular smooth muscle: $\mathrm{Mg} 2+$ versus orzzganic calcium channel blockers on myogenic tone and agonist-induced responsiveness of blood vessels. Can J Physiol Pharmacol. 1987; 65:729-745. [PubMed: 3300911]

Asaeda M, Sakamoto M, Kurosaki M, Tabuchi S, Kamitani H, Yokota M, Watanabe T. A nonenzymatic derived arachidonyl peroxide, 8-iso-prostaglandin F2 alpha, in cerebrospinal fluid of patients with aneurysmal subarachnoid hemorrhage participates in the pathogenesis of delayed cerebral vasospasm. Neurosci Lett. 2005; 373:222-225. [PubMed: 15619547]

Dacey RG Jr, Duling BR. A study of rat intracerebral arterioles: methods, morphology, and reactivity. Am J Physiol. 1982; 243:H598-H606. [PubMed: 7124967]

Dietrich HH, Dacey RG Jr. Molecular keys to the problems of cerebral vasospasm. Neurosurgery. 2000; 46:517-530. [PubMed: 10719847]

Dietrich HH, Horiuchi T, Xiang C, Hongo K, Falck JR, Dacey RG Jr. Mechanism of ATP-induced local and conducted vasomotor responses in isolated rat cerebral penetrating arterioles. J Vasc Res. 2009; 46:253-264. [PubMed: 18984964]

Dorhout Mees SM, Algra A, Vandertop WP, van Kooten F, Kuijsten HA, Boiten J, van Oostenbrugge RJ, Al-Shahi Salman R, Lavados PM, Rinkel GJ, van den Bergh WM. MASH-2 Study Group. Magnesium for aneurysmal subarachnoid haemorrhage (MASH-2): a randomised placebocontrolled trial. Lancet. 2012; 380:44-49. [PubMed: 22633825]

Eichhorn B, Dobrev D. Vascular large conductance calcium-activated potassium channels: functional role and therapeutic potential. Naunyn Schmiedebergs Arch Pharmacol. 2007; 376:145-155. [PubMed: 17932654]

Faraci FM, Heistad DD. Regulation of large cerebral arteries and cerebral microvascular pressure. Circ Res. 1990; 66:8-17. [PubMed: 2403863]

Fassbender K, Hodapp B, Rossol S, Bertsch T, Schmeck J, Schütt S, Fritzinger M, Horn P, Vajkoczy P, Wendel-Wellner M, Ragoschke A, Kuehl S, Brunner J, Schürer L, Schmiedeck P, Hennerici M. Endothelin-1 in subarachnoid hemorrhage: An acute-phase reactant produced by cerebrospinal fluid leukocytes. Stroke. 2000; 31:2971-2975. [PubMed: 11108758]

Gold ME, Buga GM, Wood KS, Byrns RE, Chaudhuri G, Ignarro LJ. Antagonistic modulatory roles of magnesium and calcium on release of endothelium-derived relaxing factor and smooth muscle tone. Circ Res. 1990; 66:355-366. [PubMed: 2153470]

Hempelmann RG, Pradel RH, Barth HL, Mehdorn HM, Ziegler A. Interactions between vasoconstrictors in isolated human cerebral arteries. Acta Neurochir (Wien). 1997; 139:574-581. [PubMed: 9248594]

Horiuchi T, Dietrich HH, Tsugane S, Dacey RG Jr. Analysis of purine- and pyrimidine-induced vascular responses in the isolated rat cerebral arteriole. Am J Physiol Heart Circ Physiol. 2001; 280:H767-H776. [PubMed: 11158976]

Ko EA, Han J, Jung ID, Park WS. Physiological roles of K+ channels in vascular smooth muscle cells. J Smooth Muscle Res. 2008; 44:65-81. [PubMed: 18552454]

$\mathrm{Ku}$ DD, Ann HS. Magnesium deficiency produces endothelium-dependent vasorelaxation in canine coronary arteries. J Pharmacol Exp Ther. 1987; 241:961-966. [PubMed: 3598912]

Longo M, Jain V, Vedernikov YP, Facchinetti F, Saade GR, Garfield RE. Endothelium dependence and gestational regulation of inhibition of vascular tone by magnesium sulfate in rat aorta. Am J Obstet Gynecol. 2001; 184:971-978. [PubMed: 11303207]

Macdonald RL. Delayed neurological deterioration after subarachnoid haemorrhage. Nat Rev Neurol. 2014; 10:44-58. [PubMed: 24323051]

Matsuda H, Saigusa A, Irisawa H. Ohmic conductance through the inwardly rectifying K channel and blocking by internal Mg2+ Nature. 1987; 325:156-159. [PubMed: 2433601] 
Mori K, Miyazaki M, Hara Y, Aiko Y, Yamamoto T, Nakao Y. Novel vasodilatory effect of intracisternal injection of magnesium sulfate solution on spastic cerebral arteries in the canine twohemorrhage model of subarachnoid hemorrhage. J Neurosurg. 2009a; 110:73-78. [PubMed: 18834261]

Mori K, Yamamoto T, Nakao Y, Osada H, Hara Y, Oyama K, Esaki T. Initial clinical experience of vasodilatory effect of intra-cisternal infusion of magnesium sulfate for the treatment of cerebral vasospasm after aneurysmal subarachnoid hemorrhage. Neurol Med Chir (Tokyo). 2009b; 49:139_ 144. [PubMed: 19398856]

Murata T, Horiuchi T, Goto T, Li Y, Hongo K. Vasomotor response induced by change of extracellular potassium and magnesium in cerebral penetrating arterioles. Neurosci Res. 2011; 70:30-34. [PubMed: 21291925]

NEILD TO. Measurement of arteriole diameter changes by analysis of television images. Blood Vessels. 1989; 26:48-52. [PubMed: 2713512]

Nishimura N, Schaffer CB, Friedman B, Lyden PD, Kleinfeld D. Penetrating arterioles are a bottleneck in the perfusion of neocortex. Proc Natl Acad Sci U S A. 2007; 104:365-370. [PubMed: 17190804]

Saito Y, Eraslan A, Lockard V, Hester RL. Role of venular endothelium in control of arteriolar diameter during functional hyperemia. Am J Physiol Heart Circ Physiol. 1994; 267:H1227H1231.

Sharma N, Cho DH, Kim SY, Bhattarai JP, Hwang PH, Han SK. Magnesium sulfate suppresses L-type calcium currents on the basilar artery smooth muscle cells in rabbits. Neurol Res. 2012; 34:291296. [PubMed: 22450340]

Shi J, Cui J. Intracellular $\mathrm{Mg}(2+)$ enhances the function of BK-type $\mathrm{Ca}(2+)$-activated $\mathrm{K}(+)$ channels. J Gen Physiol. 2001; 118:589-606. [PubMed: 11696614]

Thorneloe KS, Nelson MT. Ion channels in smooth muscle: regulators of intracellular calcium and contractility. Can J Physiol Pharmacol. 2005; 83:215-242. [PubMed: 15870837]

van den Bergh WM, Albrecht KW, Berkelbach van der Sprenkel JW, Rinkel GJ. Magnesium therapy after aneurysmal subarachnoid haemorrhage a dose-finding study for long term treatment. Acta Neurochir (Wien). 2003; 145:195-199. [PubMed: 12632115]

Veyna RS, Seyfried D, Burke DG, Zimmerman C, Mlynarek M, Nichols V, Marrocco A, Thomas AJ, Mitsias PD, Malik GM. Magnesium sulfate therapy after aneurysmal subarachnoid hemorrhage. J Neurosurg. 2002; 96:510-514. [PubMed: 11883835]

Watson KV, Moldow CF, Ogburn PL, Jacob HS. Magnesium sulfate: rationale for its use in preeclampsia. Proc Natl Acad Sci U S A. 1986; 83:1075-1078. [PubMed: 3513161]

Yang ZW, Gebrewold A, Nowakowski M, Altura BT, Altura BM. Mg(2+)-induced endotheliumdependent relaxation of blood vessels and blood pressure lowering: role of NO. Am J Physiol Regul Integr Comp Physiol. 2000; 278:R628-R639. [PubMed: 10712282]

Zhang A, Cheng TP, Altura BT, Altura BM. Extracellular magnesium regulates intracellular free Mg2+ in vascular smooth muscle cells. Pflugers Arch. 1992; 421:391-393. [PubMed: 1408664]

Zhang X, Solaro CR, Lingle CJ. Allosteric regulation of BK channel gating by $\mathrm{Ca}(2+)$ and $\mathrm{Mg}(2+)$ through a nonselective, low affinity divalent cation site. J Gen Physiol. 2001; 118:607-636. [PubMed: 11696615] 
We investigated the mechanisms and dose-dependency of magnesium-vasodilation. > Magnesium induced a concentration- and smooth muscle cell-dependent dilation. > Calcium-sensitive potassium channels of smooth muscle cells play a key role. 


\section{Magnesium-vasodilation}

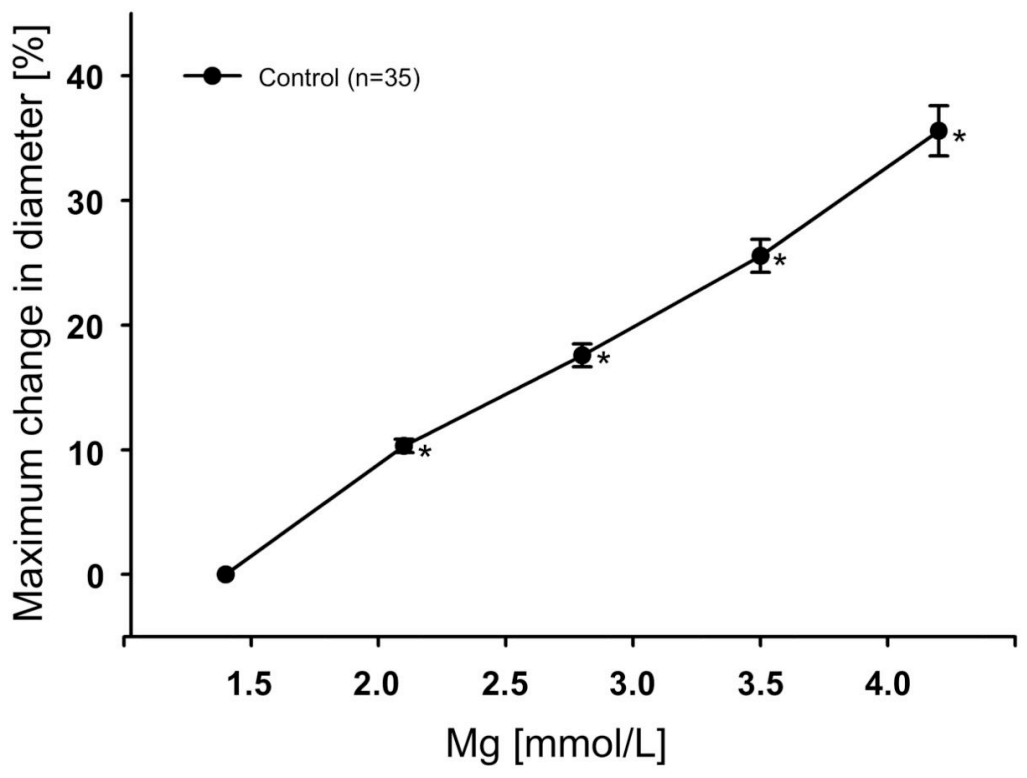

Figure 1.

Vasodilatory response to increasing concentrations of the extracellular magnesium $\left(\left[\mathrm{Mg}^{2+}\right]_{\mathrm{o}}\right)$ $(\mathrm{n}=35) .{ }^{*} P<0.05$ vs control $\left(\mathrm{Mg}^{2+}: 1.4 \mathrm{mmol} / \mathrm{L}\right)$. 
A Mg-vasodilation after endothelial impairment

B

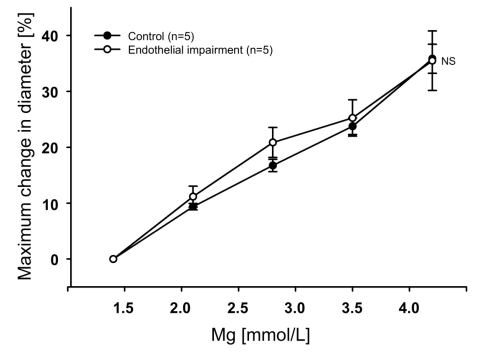

Magnesium-vasodilation with L-NNA

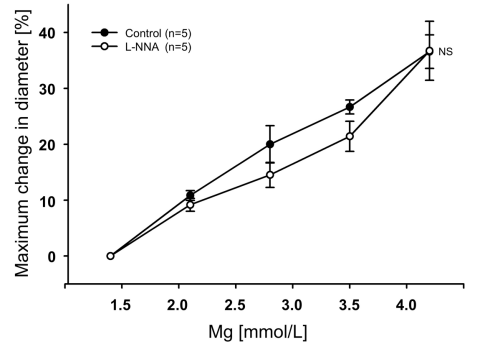

Figure 2.

Effect of endothelial impairment by air emboli $(n=5)(A)$ and endothelial nitric oxide synthase inhibition with L-NNA $(\mathrm{n}=5)(\mathrm{B})$ on the increased $\left[\mathrm{Mg}^{2+}\right]_{\mathrm{O}}$-induced dilation. NS: no significant difference. 
A Magnesium-vasodilation with TEA

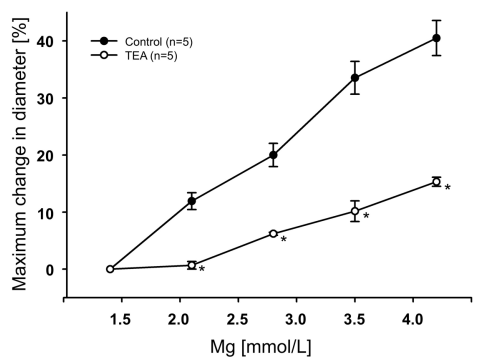

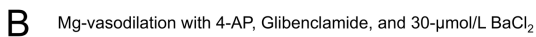

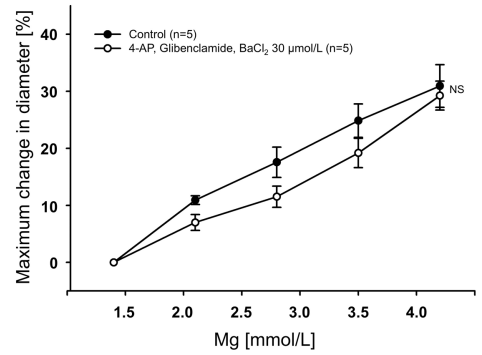

Figure 3.

Application of TEA ( $1 \mathrm{mmol} / \mathrm{L})(\mathrm{n}=5)(\mathrm{A})$ and application of $\mathrm{BaCl}_{2}(30 \mu \mathrm{mol} / \mathrm{L})$, 4-AP (100 $\mu \mathrm{mol} / \mathrm{L})$ and glibenclamide $(3 \mu \mathrm{mol} / \mathrm{L})(\mathrm{n}=5)(\mathrm{B})$ on the increased $\left[\mathrm{Mg}^{2+}\right]_{\mathrm{o}}$-induced dilation. NS: no significant difference, $* P<0.05$ vs control. 
A Magnesium-vasodilation with ET-1

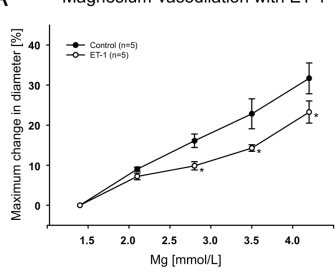

B

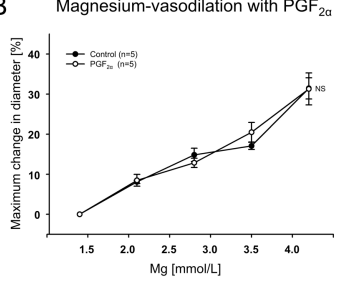

C Magnesium-vasodilation with $\mathrm{TXA}_{2}$

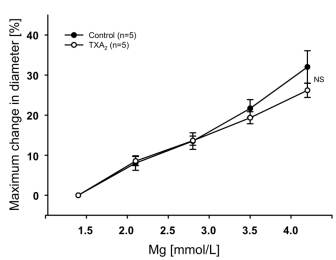

Figure 4.

Application of ET-1 (10 pmol/L) (n=5) (A), $\mathrm{PF}_{2 \mathrm{a}}(100 \mathrm{nmol} / \mathrm{L})(\mathrm{n}=5)(\mathrm{B}), \mathrm{TXA}_{2}$ analog $(10$ $\mathrm{nmol} / \mathrm{L})(\mathrm{n}=5)(\mathrm{C})$ on the increased $\left[\mathrm{Mg}^{2+}\right]_{0}$-induced dilation. NS: no significant difference, $* P<0.05$ vs control. 


\section{Table 1}

Summary of arteriolar diameter changes induced by the treatments

\begin{tabular}{|c|c|c|}
\hline inhibitor & $\mathbf{n}$ & $\%$ Relative Change in diameter (mean, SE) \\
\hline Endothelial impairment by air emboli & 5 & $-9.60 \pm 1.11 \%$ \\
\hline Endothelial NOS inhibitor (L-NNA) $10 \mu \mathrm{mol} / \mathrm{L}$ & 5 & $-10.71 \pm 1.71 \%$ \\
\hline 4-AP $100 \mu \mathrm{mol} / \mathrm{L}$, Glibenclamide $3 \mu \mathrm{mol} / \mathrm{L}$, and BaCl2 $30 \mu \mathrm{mol} / \mathrm{L}$ & 5 & $-12.43 \pm 1.50 \%$ \\
\hline TEA $1 \mathrm{mmol} / \mathrm{L}$ & 5 & $-13.29 \pm 3.38 \%$ \\
\hline Endothelin-1 $10 \mathrm{pmol} / \mathrm{L}$ & 5 & $-17.50 \pm 4.53 \%$ \\
\hline Prostaglandin F2a100 nmol/L & 5 & $-11.90 \pm 2.52 \%$ \\
\hline Thromboxane A2 analog $10 \mathrm{nmol} / \mathrm{L}$ & 5 & $-10.08 \pm 1.59 \%$ \\
\hline
\end{tabular}

